\title{
Anthropometric Assessment After Proctocolectomy Due to Ulcerative Colitis
}

\author{
HIDEJIRO KAWAHARA ${ }^{1}$, YUKI HIRAMOTO ${ }^{1}$, MITSUMASA TAKEDA ${ }^{1}$, \\ NORI MATSUMOTO $^{1}$, TAKEYUKI MISAWA ${ }^{1}$ and KATSUHIKO YANAGA ${ }^{2}$ \\ ${ }^{1}$ Department of Surgery, Kashiwa Hospital, Jikei University School of Medicine, Chiba, Japan; \\ ${ }^{2}$ Department of Surgery, Jikei University School of Medicine, Tokyo, Japan
}

\begin{abstract}
Background: Postoperative changes in patient anthropometric and nutritional statuses after proctocolectomy due to ulcerative colitis (UC) are unclear. Patients and Methods: Between January 2015 and December 2017, nine patients who underwent proctocolectomy with temporary ileostomy (PTI) for UC at our hospital were enrolled in this study. For the comparison group, eight patients who underwent low anterior resection (LAR) with temporary ileostomy for rectal cancer in the same period were recruited. Data, including body weight; body mass index (BMI); levels of total protein, albumin, cholinesterase, and hemoglobin; and lymphocyte counts, were analyzed. The changes in these parameters before surgery until 6 months after surgery were compared. Results: Before surgery, the levels of total protein, albumin, cholinesterase, hemoglobin and lymphocyte counts in the PTI group were significantly worse than those in the LAR group. However, significant differences were not identified in these factors at 1 month after surgery. The BMI was significantly lower in the PTI group than in the LAR group until 3 months after surgery. An increase in body weight to greater than that prior to surgery was found from 4 months after surgery in the PTI group. The LAR group did not have any effect of surgery in terms of any factor. Conclusion: BMI appears to be the most useful predictor of clinical and nutritional changes postoperatively.
\end{abstract}

Patients suffering from ulcerative colitis (UC) are characterized by high malnutrition rates; this is the most important patientrelated risk factor for complications after surgery $(1,2)$.

This article is freely accessible online.

Correspondence to: Hidejiro Kawahara, MD, Department of Surgery, Kashiwa Hospital, Jikei University School of Medicine, 163-1 Kashiwashita, Kashiwashi, Chiba 277-8567, Japan. Tel.: +81 471641111 Ext. 3421, Fax: +81 471633488, e-mail: kawahide@jikei.ac.jp

Key Words: Proctocolectomy, nutrition, anthropometry, ulcerative colitis.
Therefore, ways of providing nutrition and energy, thereby promoting the early recovery of patients, have become key considerations for the surgical treatment of UC. Postoperative changes in patient anthropometric and nutritional statuses after proctocolectomy due to UC remain unclear (3). The aim of this study was to identify factors predicting the clinical and nutritional changes postoperatively.

\section{Patients and Methods}

Patients. Between January 2015 and December 2017, nine patients (six males and three females) who underwent proctocolectomy with ileal pouch-anal anastomosis with temporary ileostomy (PTI) for UC were enrolled in this study. During the same period, eight male patients who underwent low anterior resection (LAR) with temporary ileostomy for lower rectal cancer at our hospital were recruited to the control group (Table I). All seventeen patients underwent ileostomy closure 6 months after surgery. Body weight and hematological/biochemical parameters were investigated to assess the nutritional status of the patients. The hematological/ biochemical parameters included the levels of total protein, albumin, cholinesterase, and hemoglobin, as well as lymphocyte counts. The preoperative body weight was measured at 1 week before surgery, and the body weight was measured again every month until 6 months after surgery. Body mass index (BMI) was calculated using the standard formula: weight $(\mathrm{kg}) / \mathrm{height}(\mathrm{m})^{2}$.

Statistical analysis. Continuous variables were expressed as the means and ranges. The Wilcoxon rank-sum test was used for the comparison of continuous variables, and the chi-square test was used for the comparison of categorical data. A p-value of less than 0.05 indicated significance. All data were analyzed using the Statistical Package for Social Sciences (SPSS) 24.0 (IBM SPSS, Tokyo, Japan).

\section{Results}

Comparison of hematological/biochemical parameters before and after surgery between the two groups. The levels of total protein, albumin, cholinesterase, and hemoglobin and the lymphocyte counts in the PTI group were significantly lower than those in the LAR group before surgery (Figures 1-5; Table I). Nevertheless, no significant differences were identified in these factors from 1 month after surgery (Table I). 


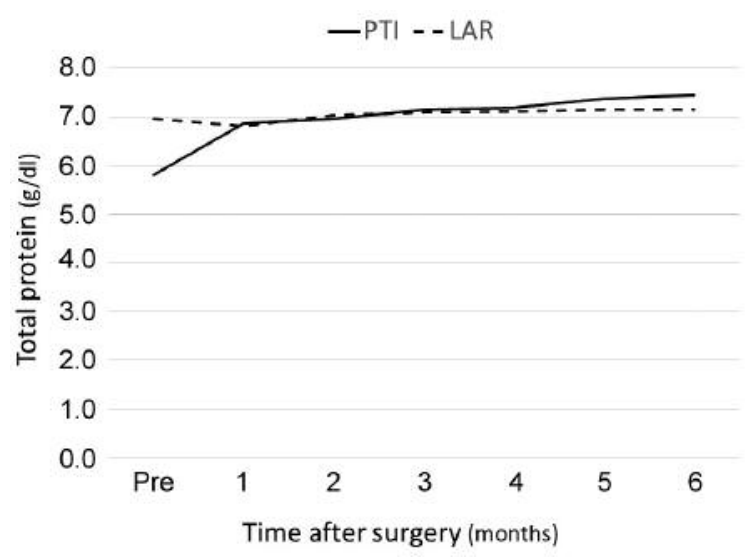

Figure 1. Course of total protein in patients of proctocolectomy $(n=9)$ (PTI) and low anterior resection ( $n=8)$ (LAR) groups during the study.

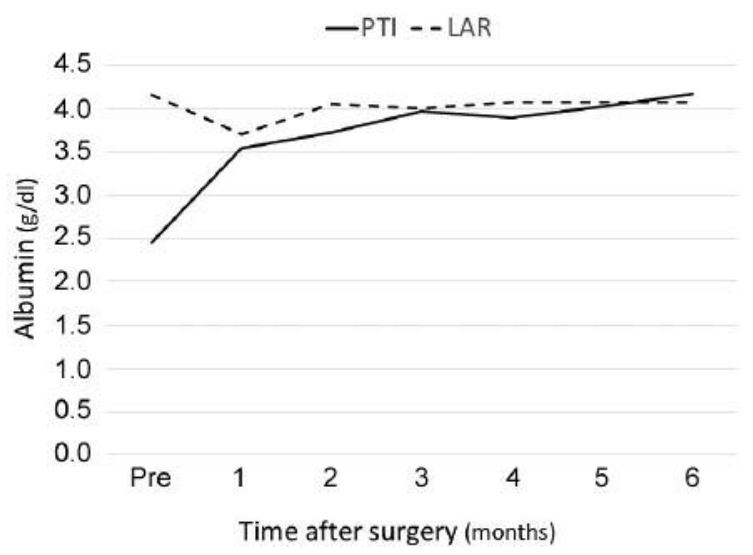

Figure 2. Course of albumin in patients of proctocolectomy ( $n=9)(P T I)$ and low anterior resection $(n=8)(L A R)$ groups during the study.

Comparison of BMI between the two groups. The BMI in the PTI group was significantly lower than that in the LAR group until 3 months after surgery (Figure 6; Table II). However, significant differences were not identified in terms of the BMI between the groups from 4 months after surgery.

Comparison of body weight changes after surgery between the two groups. The body weight loss was the greatest at 1 month after surgery in both groups, with the PTI group experiencing greater loss. Body weight gradually increased subsequently in both groups, without significant differences between groups (Figure 7; Table III). Body weight in the PTI group increased to become greater than that before surgery from 4 months after surgery.

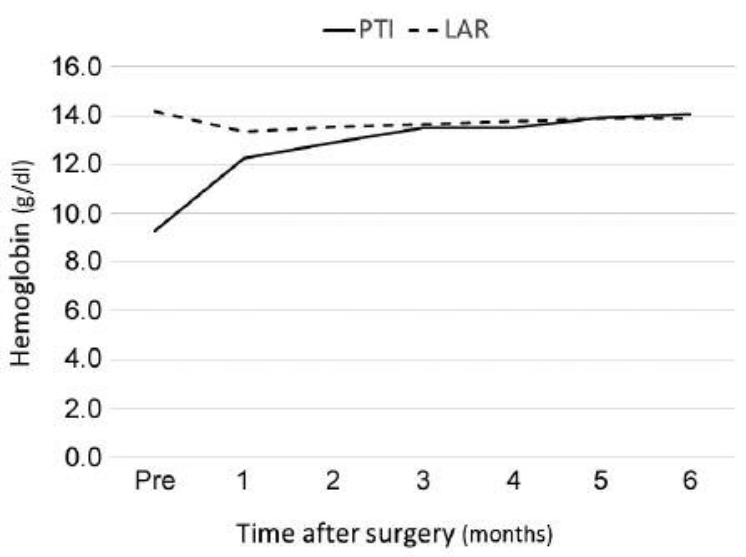

Figure 3. Course of hemoglobin in patients of proctocolectomy ( $n=9)$ (PTI) and low anterior resection $(n=8)$ (LAR) groups during the study.

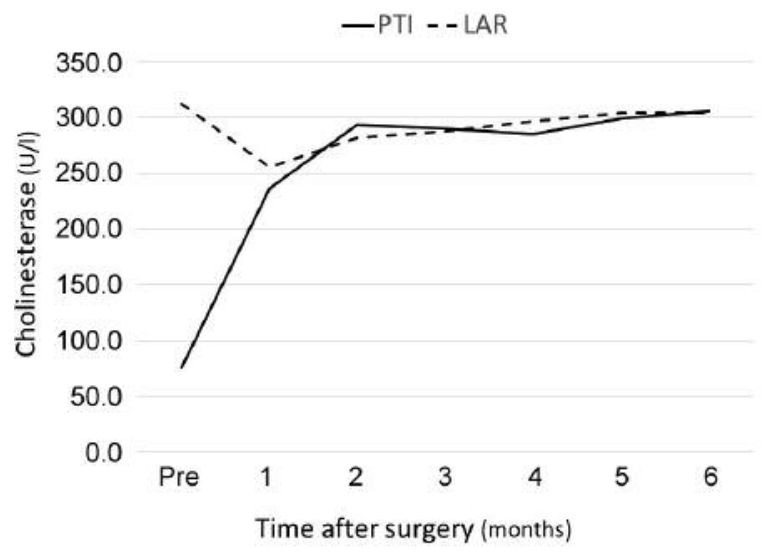

Figure 4. Course of cholinesterase in patients of proctocolectomy $(n=9)$ (PTI) and low anterior resection ( $n=8)$ (LAR) groups during the study.

\section{Discussion}

Patients suffering from UC lose nutrition because of the nature of the disease and its related clinical manifestations $(1,2)$. Approximately $23.4 \%$ of patients with UC are malnourished (4). An improved nutritional status results in lower postoperative complication rates, and in some cases can even prevent surgery by reducing the activity of the disease (5-8). When the colon and rectum are removed by proctocolectomy, the patient's digestive and absorptive functions are impaired, and their nutritional status is further worsened by stress caused by the surgery and anesthesia (9). The actual postoperative changes in anthropometric and nutritional statuses after proctocolectomy due to $\mathrm{UC}$ remain 


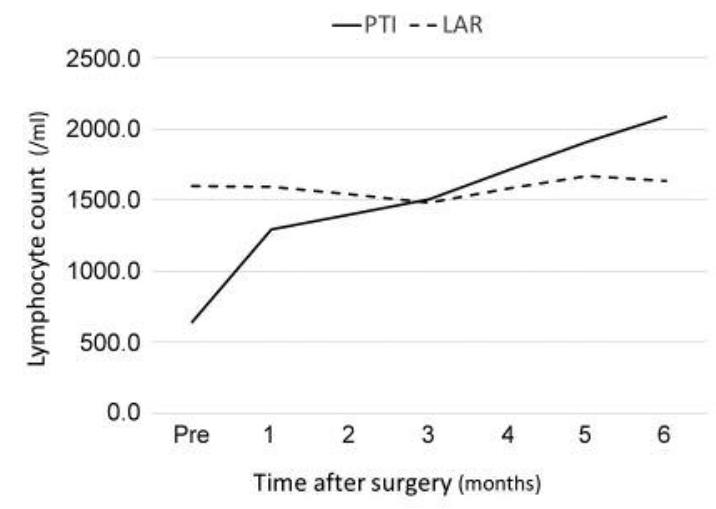

Figure 5. Course of lymphocyte counts in patients of proctocolectomy $(n=9)$ $(P T I)$ and low anterior resection $(n=8)(L A R)$ groups during the study.

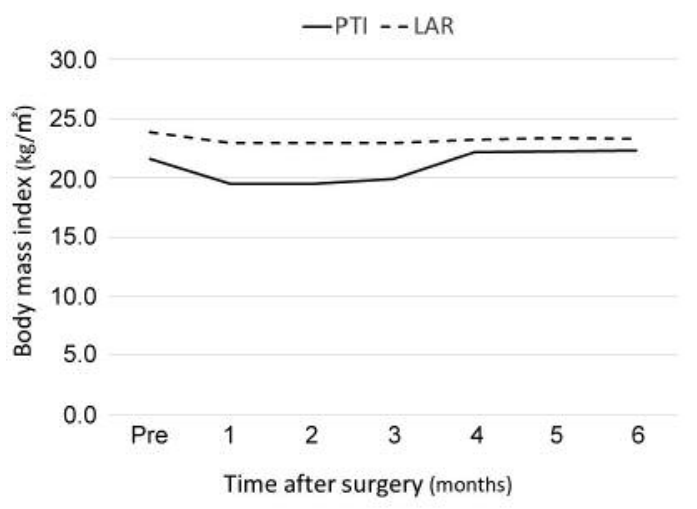

Figure 6. Course of body mass index in patients of proctocolectomy $(n=9)$ $(P T I)$ and low anterior resection $(n=8)(L A R)$ groups during the study.

Table I. Clinicopathological features of the patients.

\begin{tabular}{|c|c|c|c|c|}
\hline Characteristic & Timepoint & Proctocolectomy $(\mathrm{n}=9)$ & Low anterior resection $(\mathrm{n}=8)$ & $p$-Value \\
\hline Mean age (range), years & & $36.0(19-62)$ & $64.1(35-80)$ & $<0.001$ \\
\hline \multirow{2}{*}{ Gender, $\mathrm{n}(\%)$} & Male & $6(67)$ & $8(100)$ & 0.245 \\
\hline & Female & $3(33)$ & $0(0)$ & \\
\hline \multirow[t]{2}{*}{ Mean total protein (range), g/dl } & Before surgery & $5.8(4.9-6.7)$ & $7.0(5.9-7.7)$ & $<0.001$ \\
\hline & 1 Month after surgery & $6.9(6.4-7.3)$ & $6.8(6.2-7.3)$ & 0.724 \\
\hline \multirow[t]{2}{*}{ Mean albumin (range), g/dl } & Before surgery & $2.4(2.1-2.8)$ & $4.2(3.5-4.5)$ & $<0.001$ \\
\hline & 1 Month after surgery & $3.5(3.3-3.8)$ & $3.7(3.0-3.9)$ & 0.142 \\
\hline \multirow[t]{2}{*}{ Mean hemoglobin-(range), g/dl } & Before surgery & $9.3(8.3-10.5)$ & $14.2(12.9-15.6)$ & $<0.001$ \\
\hline & 1 Month after surgery & $12.3(10.3-14.1)$ & $13.4(11.8-14.5)$ & 0.201 \\
\hline \multirow[t]{2}{*}{ Mean ChE, (range), U/1 } & Before surgery & $75.6(61.0-90.0)$ & $312.8(2280-394.0)$ & $<0.001$ \\
\hline & 1 Month after surgery & $236.4(173.0-288.0)$ & $256.0(156.0-314.0)$ & 0.487 \\
\hline \multirow{2}{*}{ Mean lymphocyte count (range), $\mathrm{n} / \mathrm{ml}$} & Before surgery & $645.0(455.0-1542.0)$ & $1603.9(1105.0-2150.0)$ & $<0.001$ \\
\hline & 1 Month after surgery & $1294.4(1175.0-1547.0)$ & $1596.9(1104.0-1944.0)$ & 0.064 \\
\hline
\end{tabular}

ChE: Cholinesterase.

Table II. Comparison of body mass index (BMI) between groups during the study.

\begin{tabular}{|c|c|c|c|}
\hline \multirow[b]{2}{*}{ Time point relative to surgery } & \multicolumn{2}{|c|}{ Mean BMI (range), $\mathrm{kg} / \mathrm{m}^{2}$} & \multirow[b]{2}{*}{$p$-Value } \\
\hline & Proctocolectomy $(n=9)$ & Low anterior resection $(n=8)$ & \\
\hline Before & $21.6(16.4-25.7)$ & $23.9(22.0-27.1)$ & 0.298 \\
\hline After 1 month & $19.5(14.5-22.1)$ & $23.0(20.1-25.2)$ & 0.037 \\
\hline After 2 months & $19.5(13.9-22.9)$ & $22.9(19.9-25.2)$ & 0.028 \\
\hline After 3 months & $20.0(13.9-22.9)$ & $23.0(19.9-25.2)$ & 0.037 \\
\hline After 4 months & $22.2(15.8-25.0)$ & $23.3(20.0-25.3)$ & 0.908 \\
\hline After 5 months & $22.2(16.7-24.5)$ & $23.4(20.0-25.3)$ & 0.728 \\
\hline After 6 months & $22.3(16.7-24.5)$ & $23.3(20.0-25.3)$ & 0.817 \\
\hline
\end{tabular}

unclear (3). Accordingly, we tried to identify the factors predicting clinical and nutritional changes postoperatively. In this study, the levels of total protein, albumin, cholinesterase, and hemoglobin and the lymphocyte counts in the PTI group were significantly worse than those in the LAR group before surgery. However, no significant differences were identified in these factors 1 month after surgery. When the patients had resumed an adequate oral 
Table III. Comparison of body weight changes after surgery between groups during the study.

\begin{tabular}{|c|c|c|c|}
\hline \multirow[b]{2}{*}{ Time point relative to surgery } & \multicolumn{2}{|c|}{ Mean body weight change (range), $\mathrm{kg}^{*}$} & \multirow[b]{2}{*}{$p$-Value } \\
\hline & Proctocolectomy $(\mathrm{n}=9)$ & Low anterior resection $(\mathrm{n}=8)$ & \\
\hline After 1 month & $-6.0(-2.7--9.7)$ & $-2.3(-9.2-1.2)$ & 0.037 \\
\hline After 2 months & $-5.9(-2.7--11.7)$ & $-2.4(-9.2-1.2)$ & 0.082 \\
\hline After 3 months & $-4.5(-11.7-1.5)$ & $-2.3(-9.2-1.5)$ & 0.203 \\
\hline After 4 months & $2.2(-4.9-14.7)$ & $1.5(-5.0-1.5)$ & 0.163 \\
\hline After 5 months & $2.3(-4.2-14.7)$ & $1.2(-5.0-1.5)$ & 0.081 \\
\hline After 6 months & $2.6(-5.5-14.7)$ & $1.4(-5.0-1.5)$ & 0.064 \\
\hline
\end{tabular}

*Relative to pre-surgical value.

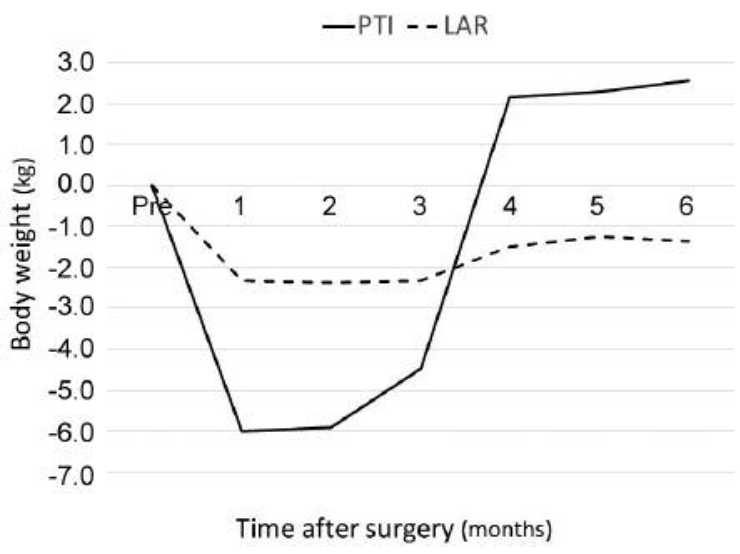

Figure 7. Change of body weight after surgery in patients of proctocolectomy $(n=9)(P T I)$ and low anterior resection $(n=8)(L A R)$ groups during the study.

intake, the levels of these factors improved immediately. Although the levels of total protein, albumin, cholinesterase, and hemoglobin and the lymphocyte counts had recovered to presurgical levels in the LAR group 1 month after surgery, body weight loss was the greatest at that time. After surgery, the change of body weight was not similar to that of the levels of these factors. Liu et al. reported that body weight loss was the greatest 3 months after surgery, and body weight gradually recovered subsequently in patients who underwent LAR (10).

On the other hand, the BMI in the PTI group was significantly worse than that in the LAR group until 3 months after surgery. However, significant differences were not identified in terms of the BMI between groups from 4 months after surgery. BMI recovery to preoperative levels was required 4 months after surgery. An increase in the body weight to more than that before surgery was found from four months after surgery.
Proctocolectomy with ileal pouch-anal anastomosis has become the gold-standard surgical treatment for UC (11). Nevertheless, some patients who have undergone this procedure continue to have postoperative problems, including malnutrition, frequent defecation and severe pouchitis (12). Temporary ileostomy appears to be closed at more than 4 months after surgery.

In conclusion, the BMI appears to be the most useful predictor of clinical and nutritional changes postoperatively.

\section{Conflicts of Interest}

The Authors declare that there are no conflicts of interest regarding this study.

\section{References}

1 Mijac DD, Janković GL, Jorga J and Krstić MN: Nutritional status in patients with active inflammatory bowel disease: prevalence of malnutrition and methods for routine nutritional assessment. Eur J Intern Med 21: 315-319, 2010.

2 Turkot M and Sobocki J: Results of home parenteral nutrition in patients with severe inflammatory bowel disease - an alternative for surgery of malnourished patients. Pol Przegl Chir 89: 23-28, 2017.

3 Sobotka LA, Husain SG, Krishna SG, Hinton A, Pavurula R, Conwell DL and Zhang C: A risk score model of 30-day readmission in ulcerative colitis after colectomy or proctectomy. Clin Transl Gastroenterol 9: 175-185, 2018.

4 Csontos ÁA, Molnár A, Piri Z, Pálfi E and Miheller P: Malnutrition risk questionnaire combined with body composition measurement in malnutrition screening in inflammatory bowel disease. Rev Esp Enferm Dig 109: 26-32, 2017.

5 Inflammatory Bowel Disease: A Global Perspective. World Gastroenterology Organisation Global Guidelines. June 2009. Available from: URL: http://www.medscape.com/index/list_7515_2.

6 Zallot C, Quilliot D, Chevaux JB, Peyrin-Biroulet C, GuéantRodriguez RM, Freling E, Collet-Fenetrier B, Williet N, Ziegler O, Bigard MA, Guéant JL and Peyrin-Biroulet L: Dietary beliefs and behavior among inflammatory bowel disease patients. Inflamm Bowel Dis 19: 66-72, 2013. 
7 Kornbluth A and Sachar DB: Practice Parameters Committee of the American College of Gastroenterology: Ulcerative colitis practice guidelines in adults: American College of Gastroenterology, Practice Parameters Committee. Am J Gastroenterol 105: 501-523, 2010.

8 Turner D, Levine A, Escher JC, Griffiths AM, Russell RK, Dignass A, Dias JA, Bronsky J, Braegger CP, Cucchiara S, de Ridder L, Fagerberg UL, Hussey S, Hugot JP, Kolacek S, Kolho KL, Lionetti P, Paerregaard A, Potapov A, Rintala R, Serban DE, Staiano A, Sweeny B, Veerman G, Veres G, Wilson DC and Ruemmele FM: Management of pediatric ulcerative colitis: Joint ECCO and ESPGHAN evidence-based consensus guidelines. J Pediatr Gastroenterol Nutr 55: 340-361, 2012.

9 Weimann A, Braga M, Carli F, Higashiguchi T, Hübner M, Klek S, Laviano A, Ljungqvist O, Lobo DN, Martindale R, Waitzberg DL, Bischoff SC and Singer P: ESPEN guideline: Clinical nutrition in surgery. Clin Nutr 36: 623-650, 2017.
10 Liu LG, Yan XB, Shan ZZ, Yan LL, Jiang CY, Zhou J, Tian Y, and Jin ZM: Anorectal functional outcome following laparoscopic low anterior resection for rectal cancer. Mol Clin Oncol 6: 613-621, 2017.

11 Mark-Christensen A, Erichsen R, Brandsborg S, Pachler FR, Nørager CB, Johansen N, Pachler JH, Thorlacius-Ussing O, Kjaer MD, Qvist N, Preisler L, Hillingsø J, Rosenberg J and Laurberg $\mathrm{S}$ : Pouch failures following ileal pouch-anal anastomosis for ulcerative colitis. Colorectal Dis 20: 44-52, 2018

12 Kühn F and Klar E: Surgical principles in the treatment of ulcerative colitis. Viszeralmedizin 31: 246-250, 2045.

Received September 13, 2018

Revised October 15, 2018

Accepted October 16, 2018 